\title{
Nanostructure Formations and Improvement in Corrosion Resistance of Steels by Means of Pulsed Electron Beam Surface Treatment
}

\author{
K. M. Zhang, ${ }^{1}$ J. X. Zou, ${ }^{2,3,4}$ and T. Grosdidier ${ }^{3,4,5}$ \\ ${ }^{1}$ School of Materials Engineering, Shanghai University of Engineering Science, Shanghai 201620, China \\ ${ }^{2}$ Shanghai Engineering Research Center of Mg Materials and Applications, National Engineering Research Center of \\ Light Alloy Net Forming, Shanghai Jiao Tong University, Shanghai 200240, China \\ ${ }^{3}$ State Key Laboratory of Metal Matrix Composite, School of Materials Science and Engineering, Shanghai Jiao Tong University, \\ Shanghai 200240, China \\ ${ }^{4}$ Laboratoire d'Etude des Microstructures et de Mécanique des Matériaux (LEM3), Université de Lorraine, Ile du Saulcy, \\ UMR 7239, 57045 Metz, France \\ ${ }^{5}$ Laboratory of Excellence on Design of Alloy Metals for Low-Mass Structures (DAMAS), University of Lorraine, 57045 Metz, France
}

Correspondence should be addressed to K. M. Zhang; zhangkm@sues.edu.cn

Received 12 December 2012; Accepted 25 January 2013

Academic Editor: Gang Ji

Copyright ( 2013 K. M. Zhang et al. This is an open access article distributed under the Creative Commons Attribution License, which permits unrestricted use, distribution, and reproduction in any medium, provided the original work is properly cited.

\begin{abstract}
The corrosion of steels has long been the topic for materials scientists. It is established that surface treatment is an efficient way to improve the corrosion resistance of steels without changing the bulk properties and with low costs. In the present paper, different kinds of surface treatment techniques for steels are briefly reviewed. In particular, the surface modification involving nanostructure formations of steels by using a low energy high pulsed electron beam (LEHCPEB) treatment is lightened in the case of an AISI 316L stainless steel and D2 steel. The overall results demonstrate the high potential of the LEHCPEB technique for improving the corrosion performance of steels.
\end{abstract}

\section{Introduction}

Steels are the most widely used metallic materials both in industrials and in our daily life. This is due to their superior properties, such as high strength, good ductility, high hardness, and low costs. However, steels often suffer from staining, rusting, and corroding in different environments [1-3], which may cause serious problems or even failure of the components made of steels. Usually, general corrosion occurs in carbon steels or low-alloyed steels since there is no dense protective films formed on these steels [4]. Therefore, the steels are continuously corroded. The so-called stainless steel usually contains $\mathrm{Cr}$ of more than $11 \mathrm{wt} \%$ [5]. As a result of the high $\mathrm{Cr}$ content, a dense protective $\mathrm{Cr}$ oxide layer can be formed on the surface in corrosive environments, which will prevent the further corrosion of the bulk material. Nevertheless, stainless steel can be affected by pitting in the presence of halide ions, particularly the chloride ion [6-8]. Therefore, corrosion resistance is of first concern for different kinds of steels to be used in industrial. The addition of alloying elements, such as $\mathrm{Cr}$, into steels is a way to improve the corrosion resistance of steels. However, alloying of the bulk material will also change the mechanical properties of the steels. Furthermore, alloying is also very costly.

To compromise the corrosion, mechanical properties, and the cost, the ideal solution would be to use surface modification techniques to generate a protective layer at the near-surface region or on the surface of the steels. In the past decades, different surface modification techniques have been applied to improve the corrosion resistance of steels. It is found that carburizing, boriding, and nitriding can be used to create a hardened layer on the steel surface, containing mainly carbides, borides, or nitrides, respectively. These hardened layers may also have better corrosion resistance 


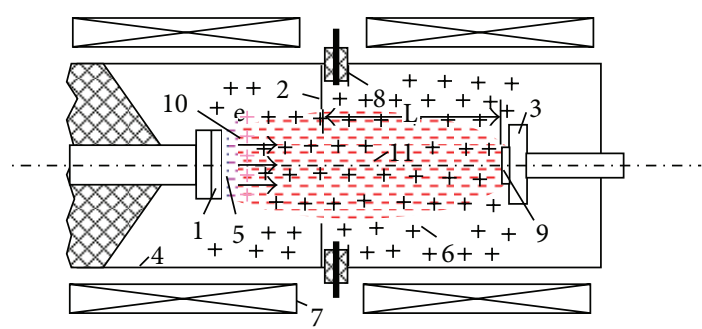
(1) Cathode
(7) Solenoid
(2) Anode
(8) Spark plasma sources
(3) Collector
(9) Specimen
(4) Vacuum chamber
(10) Plasma sheath
(5) Cathode plasma
(11)Electron beam
(6) Anode plasma

Figure 1: Schematic diagram of the LEHCPEB source based on vacuum spark plasma.

than their substrates [9-12]. By using laser surface remelting and cladding, the corrosion resistance of laser-treated steels can be also greatly improved. This was mainly attributed to a homogenization of the elements in the remelted surface layer or the addition of protective alloying elements/compounds $[13,14]$. Other methods, mainly film deposition techniques such as physical vapour deposition (PVD), chemical vapour deposition (CVD), sol-gel methods, electroless plating, and so on [15-17], have also been introduced to modify the steel surfaces. For instances, TiN, CrN, NbN, and TiCN films or multilayer films can be deposited onto steel surfaces by using various film deposition techniques [18-21]. Although these films always have better corrosion resistance, the surface properties strongly depend on the quality of the films such as pinholes and impurities, which are not easy to control. Furthermore, the films often suffer from poor adhesion with the substrates. Ion implantation is also testified to be able to improve the corrosion resistance of steels through introducing alloying elements into the very top surface layers [22-24]. However, the ion-implanted layers, usually less than $1 \mu \mathrm{m}$ in thickness, are too thin to sustain long-time corrosion.

Low Energy High Current Pulsed Electron Beam (LEHCPEB) technique is a recently developed technique for surface modification of metallic materials [25, 26]. The pulsed electron irradiation induces (i) very rapid heating, melting, solidification, and cooling of the surface together with (ii) the formation of thermal stress waves. As a result, improved surface properties of the material, often unattainable with conventional surface treatment techniques, can be obtained fairly easily. This is particularly true for tribological properties [27-29]. Previous investigations have suggested that the LEHCPEB technique could be also used to improve the corrosion resistance of precipitates containing alloys [30-32]. The pulsed electron irradiation generated by this surface treatment technique induces rapid melting of the surface followed by extremely fast solidification. This process leads to the dissolution of second-phase particles and, after sufficient number of pulses, to the formation of a
2-3 $\mu \mathrm{m}$ thick homogeneous melted surface [33]. In the case of the steels, the subsequent ultra-fast solidification leads to a structure containing nanostructured domains [34]. It will be shown in the following sections that those effects induced by the LEHCPEB treatments can significantly improve the corrosion resistance of steels.

\section{The LEHCPEB System}

The pulsed electron beam treatment was carried out with a Nadezhda-2 type LEHCPEB source $[25,35]$. It produces an electron beam of low energy (10-40 keV), high-peak current $\left(10^{2}-10^{3} \mathrm{~A} / \mathrm{cm}^{2}\right)$, short pulse duration (approx.1 $\left.\mu \mathrm{s}\right)$, and high efficiency (repeating pulse interval being $10 \mathrm{~s}$ ). Figure 1 shows a detailed sketch of the electron beam gun, a major part of the electron beam system which produces electron beams. The explosive emission cathode is made of porous graphite for its low ionization potential. The anode is made of stainless steel and has a hole in its center through which the beam passes. Graphite cathode spark plasma sources are placed evenly in a circle behind the anode. The electron beam is transported through the anode plasma to the collector. To prevent the beam from pinching and dispersing, an external magnetic field created by a sectioned solenoid is used. The accelerating voltage, magnetic field intensity, and anode-collector distance control the beam energy density. More details about the LEHCPEB system can be found in $[35,36]$.

\section{Surface Modifications of Steels by the LEHCPEB Treatment}

Two examples of steels treated by the LEHCPEB are shown here, namely, AISI 316L stainless steel and AISI D2 steel. The details about the starting materials and their LEHCPEB treatments can be found in [32-34]. In both cases, the modifications in microstructure and corrosion resistance induced by the treatment will be reviewed and discussed in detail.

3.1. Improving Corrosion Resistance of $316 L$ Stainless Steel by $L E H C P E B$. Figure 2(a) shows a SEM image of the microstructure of the AISI 316L stainless steel in the asreceived condition after etching in chloronitrous acid and observation under secondary electron imaging (SEI) condition. The microstructure is primarily a single austenitic phase structure. Many of the grains are twinned, and their size is about $40 \sim 60 \mu \mathrm{m}$. Figure 2(b) is a backscattered electron image (BEI) of the untreated sample. The composition is fairly homogenous on the whole surface, but many tiny inclusions are visible. These inclusions are the intentionally introduced MnS particles [37] improving machinability. Electron probe microanalysis was also carried out on the treated samples to reveal the possible composition changes in the LEHCPEBtreated samples. Figure 3 shows the results from the samples treated for 5 and 20 pulses with a beam energy of $3 \mathrm{~J} / \mathrm{cm}^{2}$. Figure 3(a) is a secondary electron image of the sample treated for 5 pulses, and Figure $3(\mathrm{~b})$ is the corresponding backscattered electron image. In Figure 3(a), a large amount 


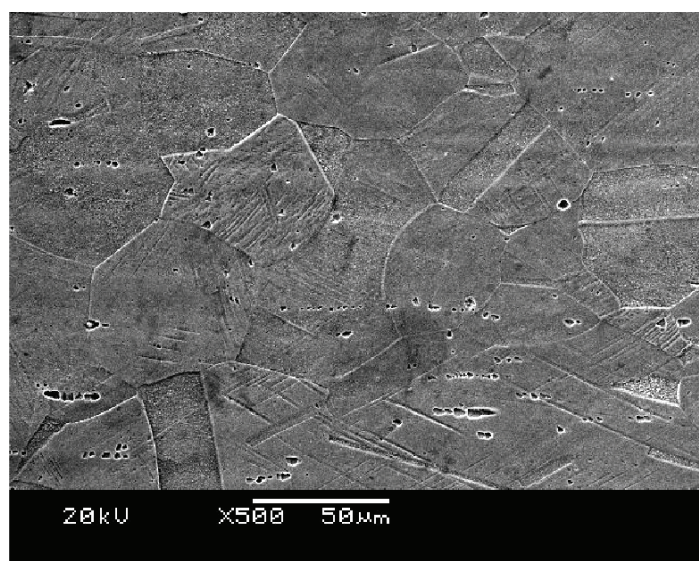

(a)

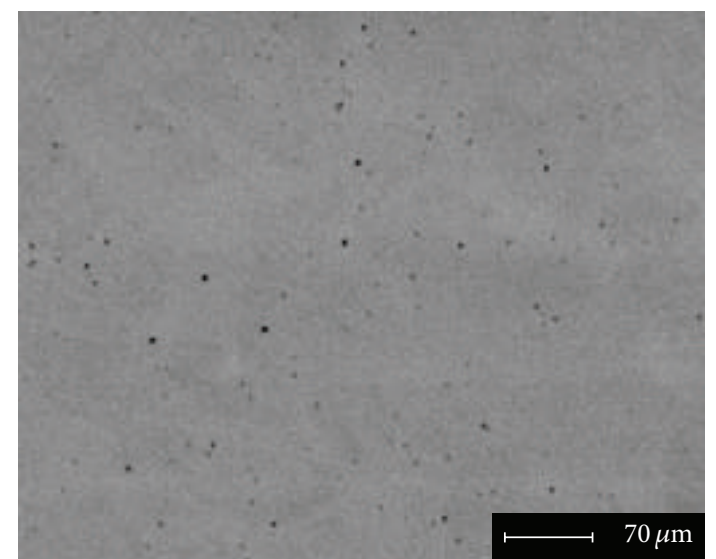

(b)

FIGURE 2: SEM images obtained under SEI (a) and BEI (b) imaging conditions for the initial sample.

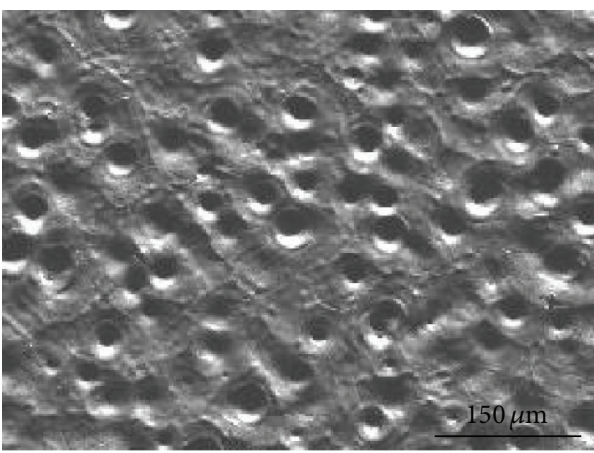

(a)

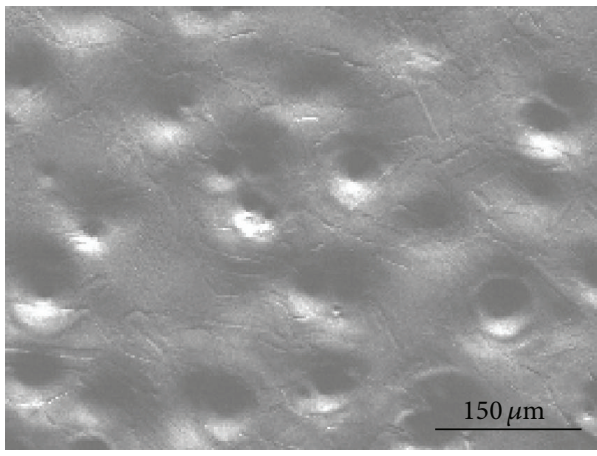

(c)

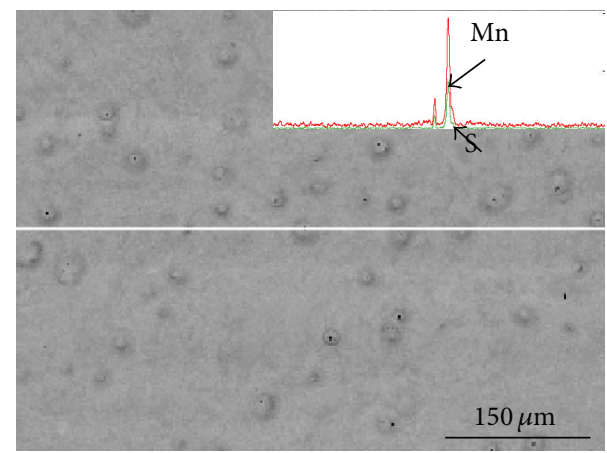

(b)

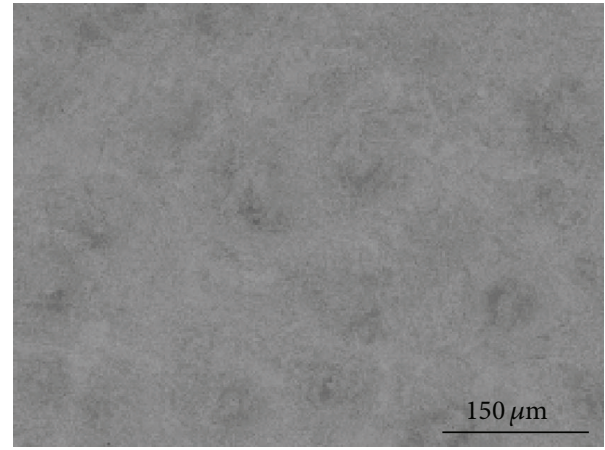

(d)

FIGURE 3: Images of the samples treated for 5 ((a) and (b)) and 20 ((c) and (d)) pulses observed under SEI ((a) and (c)) and BEI ((b) and (d)) conditions.

of craters can be observed, which are commonly present on metal surfaces treated with pulsed energetic beams [38, 39]. They are distributed fairly homogeneously on the whole surface. In Figure 3(b), some dark spots still exist on the surface, but their quantity is reduced compared to the initial state. Comparing Figures 3(a) and 3(b), it is clear that the dark spots are always located at the center of the craters. The elemental line scan shown in Figure 3(b) reveals that the dark spots correspond to S- and Mn-rich particles or $\mathrm{MnS}$ inclusions. The previously mentioned result indicates that the MnS particles initiate the craters. Figures 3(c) and $3(\mathrm{~d})$ display the same analysis for the 20-pulse sample. In Figure 3(c), only a few craters are present after 20 pulses. The crater density is much lower than the one reported for the 5-pulse treatment. Figure 3(d) shows that the dark spots have almost completely disappeared. In brief, the second phase particles are the nucleation sites for craters during the LEHCPEB treatment.

A typical example of SNMS analysis in 20-pulse sample is given in Figure 4 where the evolutions in the $\mathrm{Fe}, \mathrm{Cr}, \mathrm{Ni}$, 


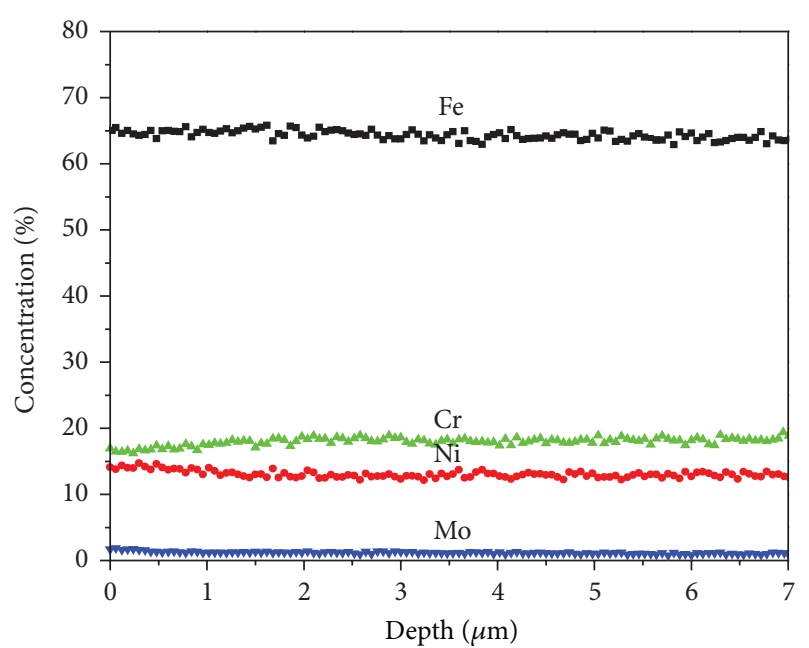

(a)

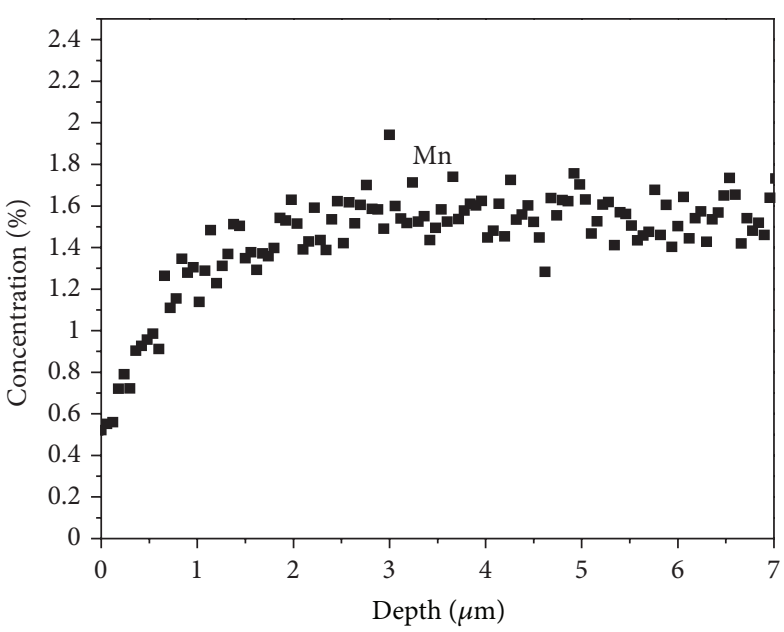

(b)

FIGURE 4: A typical example of surface composition profiles of the 316L stainless steel sample treated by LEHCPEB for 20 pulses measured by SNMS.

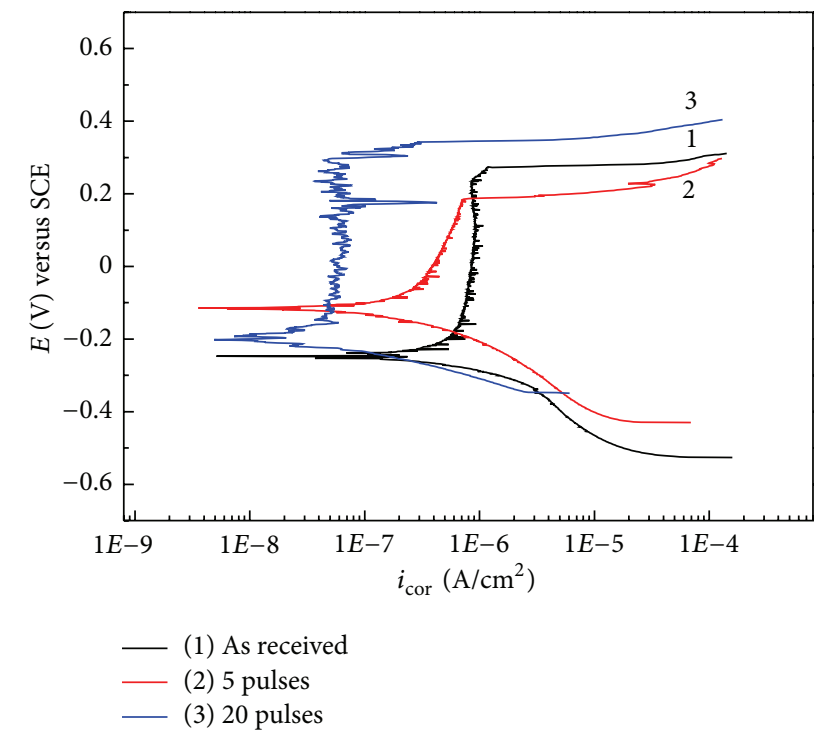

FIGURE 5: Potentiodynamic polarization curves of the treated and untreated AISI 316L stainless steel in the TSB fluid.

Mo, and Mn concentrations are plotted as a function of the distance from the surface. After 20 pulses, as illustrated in Figure 4(a), the Fe, Ni, Cr, and Mo concentrations remained nearly constant. On the other hand, the Mn concentration decreases significantly toward the surface from 1.6 at. \% in the bulk of the steel down to about 0.6 at. \% at the top surface, as shown in Figure 4(b). Considering that a part of Mn exists in MnS particles, the decrease in Mn concentration in the surface layer confirmed the occurrence of the selective purification effect during the LEHCPEB treatment.

Figure 5 shows the results of the potentiodynamic polarization curves of the untreated and treated samples. All the samples have a passive behavior in the Tyrode's simulated body fluid (TSBF) solution. The corrosion current density of the LEHCPEB-treated samples decreased when increasing the pulse numbers. The corrosion current density of the sample after 20 pulses was an order of magnitude lower than that of the untreated sample. The corrosion potential $\left(E_{\text {corr }}\right)$ of all the treated samples is also increased to some extent. The breakdown potential of the passive film, $E_{\mathrm{brk}}$, increases from $233 \mathrm{mV}$ (SCE) for the untreated sample to $342 \mathrm{mV}$ for the 20-pulsed sample. These polarization curves reveal a significant improvement in the corrosion resistance of the 316L stainless steel after the LEHCPEB treatment. However, the results also show that the 5-pulse sample has a lower broken potential with a narrower passive region compared to that of the untreated sample.

Figure 6 shows the Bode plots of EIS spectra for all the $316 \mathrm{~L}$ stainless steel samples in the TSB fluid. In the high-frequency region, the impedance reflects the electrolyte resistance between the sample and the reference electrode. At the low-frequency limit, the impedance is attributed to the polarization resistance of the sample in the electrolyte [40]. It is clear that the impedance modulus and the phase angle of the initial sample are always lower than those of the treated samples. From Figure 6(a), it can be seen that $|Z|$ has a nearly linear relation with $\log (f)$. Figure $6(\mathrm{~b})$ indicates that the phase angle $\phi$ has values close to $-80^{\circ}$ at lowfrequency values $(f<1 \mathrm{~Hz})$ after the LEHCPEB treatments. These characteristics indicate that the oxide layer formed on modified samples has predominantly a capacitive behavior [41]. The near capacitive behavior is observed over a wider frequency range for the modified samples. This means that the passive film on the LEHCPEB-modified sample surface can maintain its characteristic response over a longer time. Moreover, the 20-pulse sample displayed higher polarization resistance compared with that of 5-pulse one. This can be observed in both the higher near capacitive values of the phase shift response at low frequencies and in the impedance values at low frequency. From all of the previously mentioned results, we can safely conclude that the corrosion resistance 


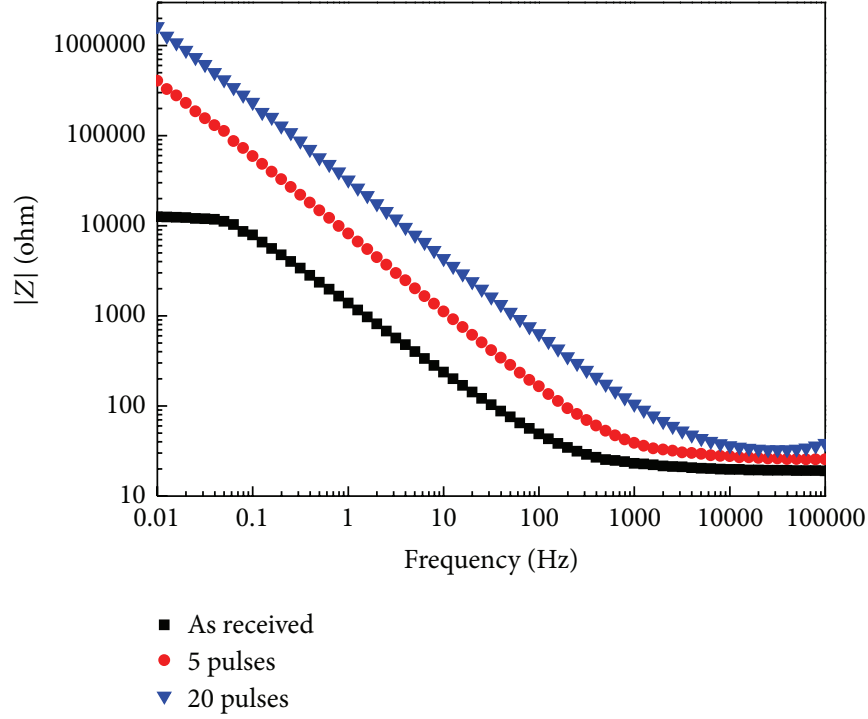

(a)

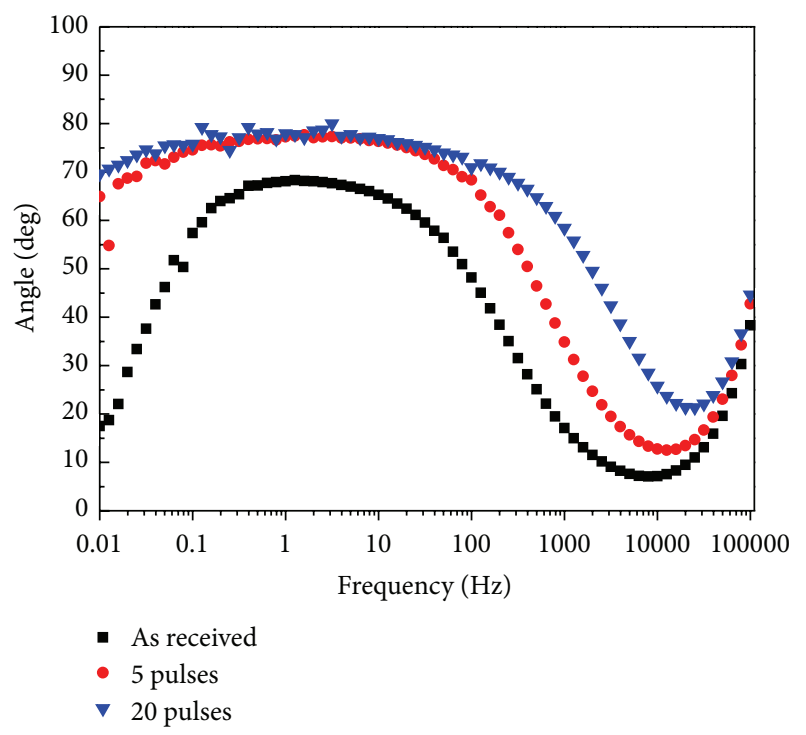

(b)

FIGURE 6: Bode plots of 316L samples in the TSB fluid: (a) impedance modulus $|Z|$ versus frequency $f$, (b) phase angle $\phi$ versus frequency.

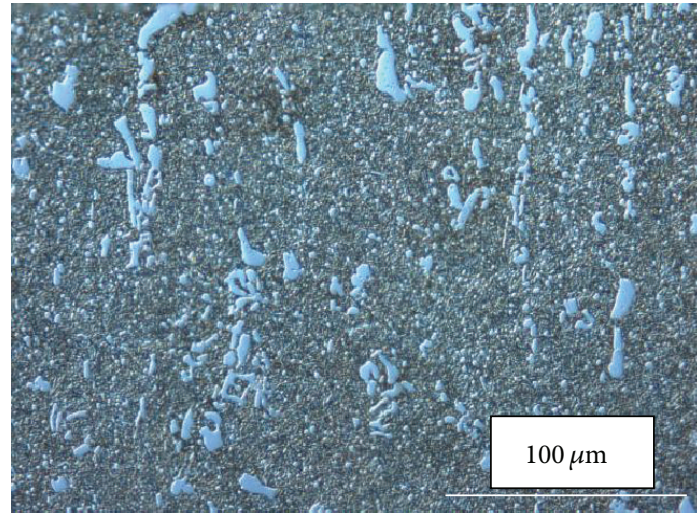

(a)

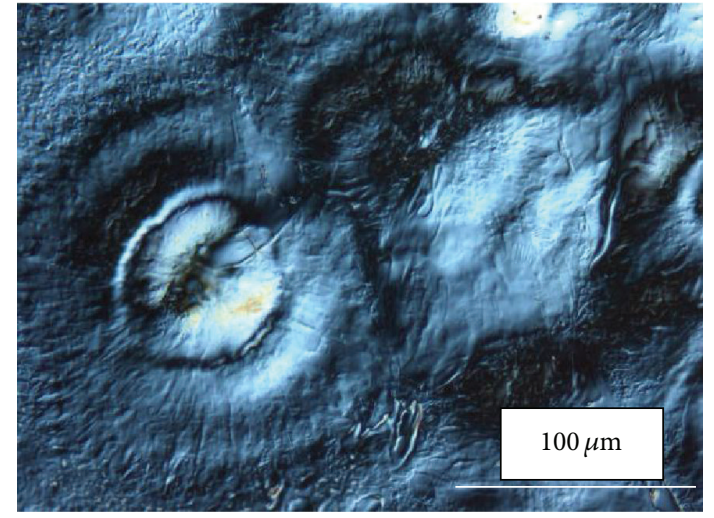

(b)

FIGURE 7: Optical morphologies of the D2 samples: as initial (a), treated sample D2-1 (b).

of samples was significantly improved after the LEHCPEB treatment. The best corrosion resistance in this study was found to be the sample treated with 20 pulses.

The crater formation and related surface purification effect are believed to be the main reasons for the improved corrosion resistance. At the early stage of the treatment, typically 5 pulses in our case, eruption usually occurs on the top surface, since there are a large amount of inclusions/secondphase particles. With the increased number of pulses, the particle density on the top surface decreases due to the eruption events as well as their dissolution within the melt. This reduction of particle density leads to a lower amount of available nucleation sites for new eruption events and, consequently, the crater formation on the top surface is more difficult. Since the solidification rate is very fast, "solute trapping" occurs under cooling after the dissolution of the particles and results in the homogenization of the chemistry in the resolidified melted layer. This removes the Cr-depleted zone generally present at the material surface [8] and enhances the corrosion resistance. The best corrosion properties are obtained after a sufficient number of LEHCBEB pulses-typically 20 pulses here-that can provide with the combination of (i) the formation of a chemically homogeneous film and (ii) the absence of surface craters.

By using the LEHCPEB treatment, rapid surface alloying of the $316 \mathrm{~L}$ stainless steel with $\mathrm{Ti}$ has been successfully achieved. The results showed that the corrosion resistance of the steel can be further improved by introducing Ti into the top surface layer of the stainless steel [42].

3.2. Improving Corrosion Resistance of D2 Steel by LEHCPEB. The pulsed electron beam treatment parameters for the D2 steel samples are shown in Table 1. Here, the number of pulses is set as 20 for all the samples, while the accelerating voltage is changed. Figures 7(a) and 7(b) give the typical optical images 


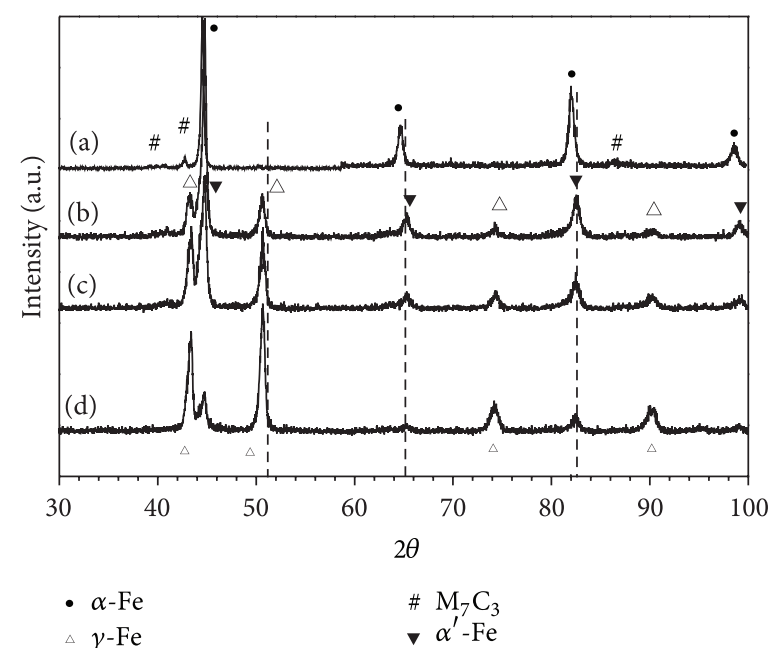

FIGURE 8: XRD patterns of the untreated and treated D2 steel samples, as received (a), D2-1 (b), D2-2 (c), and D2-3 (d).

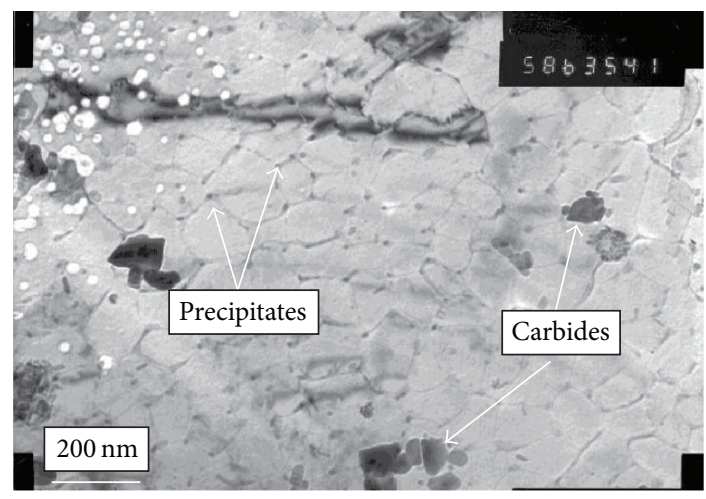

FIGURE 9: Typical bright field TEM micrograph taken in the melted layer of the 25-pulse D2 steel sample.

of the untreated and treated D2 steel (D2-1) samples. It can be clearly seen that large carbides are present in the untreated sample (Figure 7(a)). After the treatment, craters are formed on the surface (Figure 7(b)), which are the results of eruptions occurring at the carbides. Indeed, the carbides have lower melting point and heat conductivity than the $\alpha$ ferrite matrix. Therefore, during the treatment process, the carbides melt before the rest of the material. Just below the surface, the melting expansion induces an eruption event, as described in more detail elsewhere [34, 43].

Figure 8 shows the XRD traces of the samples before and after the LEHCPEB treatments. The starting material contained two phases: ferrite $(\alpha-\mathrm{Fe})$ and carbide having the $\mathrm{Cr}_{7} \mathrm{C}_{3}$ structure. The volume fraction of the carbide is fairly important, and the carbide peaks are clearly visible in the $\mathrm{XRD}$ trace of the starting material. The intensity of the Xray diffraction peaks also indicates that the major phase in the initial material was $\alpha$-ferrite. After the LEHCPEB bombardment, the XRD traces are observed to change somehow dramatically. Concerning the $\mathrm{Cr}_{7} \mathrm{C}_{3}$ phase, it is clear that the carbide peaks tend to disappear after the LEHCPEB
TABLE 1: LEHCPEB treatment parameters of the D2 steel samples.

\begin{tabular}{ccccc}
\hline \multicolumn{2}{c}{ Specimens } & $\begin{array}{c}\text { Energy } \\
(\mathrm{kV})\end{array}$ & $\begin{array}{c}\text { Distance } \\
(\mathrm{mm})\end{array}$ & $\begin{array}{c}\text { Pulses } \\
\text { (times) }\end{array}$ \\
\hline \multirow{3}{*}{ D2 } & D2-1 & 18.00 & 140 & 20 \\
& D2-2 & 21.50 & 140 & 20 \\
& D2-3 & 27.80 & 140 & 20 \\
\hline
\end{tabular}

TABLE 2: Corrosion data of the untreated and treated D2 steel samples in $3.5 \% \mathrm{NaCl}$ solution.

\begin{tabular}{lccc}
\hline Samples & $\begin{array}{l}E_{\text {corr }} \\
(\mathrm{mV})\end{array}$ & $\begin{array}{c}i_{\text {corr }} \\
\left(\mu \mathrm{A} / \mathrm{cm}^{2}\right)\end{array}$ & $\begin{array}{c}R_{p} \\
\left(\mathrm{k} \Omega / \mathrm{cm}^{2}\right)\end{array}$ \\
\hline As initial & -720.38 & 0.29 & 74.37 \\
D2-1 & -451.45 & 0.23 & 93.06 \\
D2-2 & -470.77 & 0.21 & 101.27 \\
D2-3 & -478.14 & 0.20 & 105.69 \\
\hline
\end{tabular}

treatments. Concerning the $\alpha$ phase, it is interesting to note that some of the peaks in the treated samples have close neighbours. A splitting of the (200) peak is usually found in newly formed martensite having sufficient amount of $\mathrm{C}$ to reveal its quadraticity. Finally, some new peaks are present in the XRD traces. They were verified to be from the $\gamma$-Fe phase. The peak intensity of the $\gamma$-Fe phase increases with the accelerating voltage, indicating that the volume fraction of the $\gamma$ phase detected by XRD increases $[44,45]$.

The corrosion resistance of the D2 steels samples was measured in the $3.5 \% \mathrm{NaCl}$ water solution. The corrosion data calculated from potentiodynamic polarization tests are summarized in Table 2. It can be found that the corrosion potential $\left(E_{\text {corr }}\right)$ becomes nobler after the LEHCPEB treatment, while the corrosion current $\left(i_{\text {corr }}\right)$ decreases. As a result, the calculated polarization resistance $\left(R_{p}\right)$ increases after the LEHCPEB treatment. The best corrosion resistance is found in the D2 steel sample treated with the highest accelerating voltage (D2-3).

The corrosion resistance of D2 steel is closely related to the formation of austenite in the surface layer. From the phase diagram, it can be established that the primary phase in solidification for the D2 steel should be $\gamma$. However, the local composition depends on the ability of electron beam to homogenize the surface layer. When the accelerating voltage is low, that is, low beam energy density, the melting duration of the surface layer is very short. As a result, the large carbides cannot be completely dissolved in the melt. During cooling, martensitic transformation will occur in the $\mathrm{Clean}$ austenite. When high-accelerating voltage is applied, the melt duration at the top surface layer is sufficient long for carbides to be completely dissolved. The austenite layer formed in the melted layer will be stabilized by $\mathrm{C}$ and retained at room temperature. Figure 9 shows a typical TEM bright field image of the austenite layer formed in a D2 steel sample treated by 25 pulses [34]. It is clearly seen that the austenite phase has a celllike structure with a cell size of about 100 200 nm. Besides, some nanoscale carbides and precipitates are also visible at the boundary or the triple junctions of the cells. Such kind 
of nanocell/grain structure was also observed in other steels, $\mathrm{Mg}, \mathrm{Al}$ alloys treated by pulsed electron beams [46-50]. The presence of these metastable homogeneous layers with special nanostructures formed by the LEHCPEB treatment at the top surface accounts for the improved corrosion resistance of the treated samples. The advantages of the LEHCPEB treatment over other conventional surface treatment techniques lie in (i) the formation of homogeneous surface layers having nanostructures after a sufficient number of pulses [30-36]; (ii) the strong metallurgical binder between treated layers and the substrate [25, 32-34]; and (iii) the thick modified layer after the LEHCPEB treatment $[25,26,36,38]$. Therefore, the LEHCPEB technique is a promising approach in improving the surface properties of metallic materials, especially their corrosion resistance.

\section{Summary}

The modifications in microstructures and corrosion after low energy high current pulsed electron beam (LEHCPEB) surface treatment have been shown in the case of steels. The results obtained here for the AISI 316L stainless steel and AISI D2 steel clearly confirm the high potential of the LEHCPEB technique for improving the corrosion resistance; in particular if the number of pulses and/or the beam energy is sufficiently high. The crater eruption-induced purification effect and the formations of homogenized layer and nanostructures are believed to be the main reasons accounting for the improved corrosion resistance of steels after the LEHCPEB treatment.

\section{Acknowledgments}

Professor K. M. Zhang would like to acknowledge the support of Top Discipline Plan for Mechanical Engineering of Shanghai Municipal Education Commission (YLJX12-2). This work is supported by the Special Foundation of the Shanghai Science and Technology Committee for Nanomaterials Research (no. 1052nm05000) and National Natural Science Foundation (nos. 51101096, 51271121). Professor T. Grosdidier would also like to acknowledge the "Sea-Sky" professorship position provided by the Dalian University of Technology. Finally, Professor T. Grosdidier and J. X. Zou would like to acknowledge the framework of the Labex DAMAS within which this work was carried out.

\section{References}

[1] A. S. Cushman and H. A. Gardner, The Corrosion and Preservation of Iron and Steel, McGraw-Hill, New York, NY, USA, 1910.

[2] M. G. Fontana and N. D. Greene, Corrosion Engineering, McGraw-Hill, New York, NY, USA, 1967.

[3] K. R. Trethewey and J. Chamberlain, Corrosion for Students of Science and Engineering, Longman Scientific and Technical, Burnt Mill, UK, 1988.

[4] P. R. Roberge, Corrosion Basics: An Introduction, NACE Press, 2nd edition, 2006.
[5] K. H. Lo, C. H. Shek, and J. K. L. Lai, "Recent developments in stainless steels," Materials Science and Engineering R: Reports, vol. 65, no. 4-6, pp. 39-104, 2009.

[6] G. Wranglen, "Pitting and sulphide inclusions in steel," Corrosion Science, vol. 14, no. 5, pp. 331-349, 1974.

[7] G. S. Eklund, "Initiation of pitting at sulfide inclusions in stainless steel," Journal of the Electrochemical Society, vol. 121, no. 4, pp. 467-473, 1974.

[8] M. P. Ryan, D. E. Williams, R. J. Chater, B. M. Hutton, and D. S. McPhail, "Why stainless steel corrodes," Nature, vol. 415, no. 6873, pp. 770-774, 2002.

[9] C. Bindal and A. H. Ucisik, "Characterization of boriding of 0.3\%C, $0.02 \%$ P plain carbon steel," Vacuum, vol. 82, no. 1, pp. 90-94, 2007.

[10] A. Pertek and M. Kulka, "Two-step treatment carburizing followed by boriding on medium-carbon steel," Surface and Coatings Technology, vol. 173, no. 2-3, pp. 309-314, 2003.

[11] B. Selçuk, R. Ipek, M. B. Karamiş, and V. Kuzucu, "An investigation on surface properties of treated low carbon and alloyed steels (bonding and carburizing)," Journal of Materials Processing Technology, vol. 103, no. 2, pp. 310-317, 2000.

[12] A. A. Novakova, I. G. Sizov, D. S. Golubok, T. Y. Kiseleva, and P. O. Revokatov, "Electron-beam boriding of low-carbon steel," Journal of Alloys and Compounds, vol. 383, no. 1-2, pp. 108-112, 2004.

[13] T. M. Yue, J. K. Yu, and H. C. Man, "The effect of excimer laser surface treatment on pitting corrosion resistance of 316LS stainless steel," Surface and Coatings Technology, vol. 137, no. 1, pp. 65-71, 2001.

[14] I. Manna, J. Dutta Majumdar, B. Ramesh Chandra, S. Nayak, and N. B. Dahotre, "Laser surface cladding of Fe-B-C, Fe-B-Si and Fe-BC-Si-Al-C on plain carbon steel," Surface and Coatings Technology, vol. 201, no. 1-2, pp. 434-440, 2006.

[15] C. J. Wang and C. C. Li, "Corrosion behaviors of AISI 1025 steels with electroless nickel/aluminized coatings in $\mathrm{NaCl}$-induced hot corrosion," Surface and Coatings Technology, vol. 177-178, pp. 37-43, 2004.

[16] J. S. Chen, J. G. Duh, and F. B. Wu, "Microhardness and corrosion behavior in $\mathrm{CrN} /$ electroless $\mathrm{Ni} /$ mild steel complex coating," Surface and Coatings Technology, vol. 150, no. 2-3, pp. 239-245, 2002.

[17] B. F. Chen, W. L. Pan, G. P. Yu, J. Hwang, and J. H. Huang, "On the corrosion behavior of TiN-coated AISI D2 steel," Surface and Coatings Technology, vol. 111, no. 1, pp. 16-21, 1999.

[18] E. Lunarska, N. Ageeva, and J. Michalski, "Corrosion resistance of plasma-assisted chemical vapour deposition (PACVD) TiNcoated steel in a range of aggressive environments," Surface and Coatings Technology, vol. 85, no. 3, pp. 125-130, 1996.

[19] J. Creus, H. Idrissi, H. Mazille, F. Sanchette, and P. Jacquot, "Improvement of the corrosion resistance of CrN coated steel by an interlayer," Surface and Coatings Technology, vol. 107, no. 2-3, pp. 183-190, 1998.

[20] L. A. S. Ries, D. S. Azambuja, and I. J. R. Baumvol, "Corrosion resistance of steel coated with Ti/TiN multilayers," Surface and Coatings Technology, vol. 89, no. 1-2, pp. 114-120, 1997.

[21] C. Liu, Q. Bi, and A. Matthews, "EIS comparison on corrosion performance of PVD TiN and CrN coated mild steel in $0.5 \mathrm{~N}$ $\mathrm{NaCl}$ aqueous solution," Corrosion Science, vol. 43, no. 10, pp. 1953-1961, 2001.

[22] E. Cano, L. Martínez, J. Simancas, F. J. Pérez-Trujillo, C. Gómez, and J. M. Bastidas, "Influence of N, Ar and Si ion implantation 
on the passive layer and corrosion behaviour of AISI 304 and 430 stainless steels," Surface and Coatings Technology, vol. 200, no. 16-17, pp. 5123-5131, 2006.

[23] N. Mottu, M. Vayer, J. Dudognon, and R. Erre, "Structure and composition effects on pitting corrosion resistance of austenitic stainless steel after molybdenum ion implantation," Surface and Coatings Technology, vol. 200, no. 7, pp. 2131-2136, 2005.

[24] F. J. Pérez, E. Otero, M. P. Hierro et al., "High temperature corrosion protection of austenitic AISI 304 stainless steel by $\mathrm{Si}$, Mo and Ce ion implantation," Surface and Coatings Technology, vol. 108-109, no. 1-3, pp. 127-131, 1998.

[25] D. I. Proskurovsky, V. P. Rotshtein, G. E. Ozur et al., "Pulsed electron-beam technology for surface modification of metallic materials," Journal of Vacuum Science and Technology A, vol. 16, no. 4, pp. 2480-2488, 1998.

[26] D. I. Proskurovsky, V. P. Rotshtein, G. E. Ozur, Y. F. Ivanov, and A. B. Markov, "Physical foundations for surface treatment of materials with low energy, high current electron beams," Surface and Coatings Technology, vol. 125, no. 1-3, pp. 49-56, 2000.

[27] A. D. Pogrebnjak, V. S. Ladysev, N. A. Pogrebnjak et al., "Comparison of radiation damage and mechanical and tribological properties of $\alpha$-Fe exposed to intense pulsed electron and ion beams," Vacuum, vol. 58, no. 1, pp. 45-52, 2000.

[28] A. N. Valyaev, V. S. Ladysev, A. D. Pogrebnjak, A. A. Valyaev, and S. V. Plotnikov, "Comparative analysis of radiation damages, mechanical and tribological properties of $\alpha$-Fe exposed to intense-pulsed electron and ion beams," Nuclear Instruments and Methods in Physics Research B, vol. 161, pp. 1132-1136, 2000.

[29] B. Gao, S. Hao, J. Zou et al., "High current pulsed electron beam treatment of AZ31 Mg alloy," Journal of Vacuum Science and Technology A, vol. 23, no. 6, pp. 1548-1553, 2005.

[30] J. X. Zou, K. M. Zhang, C. Dong, Y. Qin, S. Hao, and T. Grosdidier, "Selective surface purification via crater eruption under pulsed electron beam irradiation," Applied Physics Letters, vol. 89, no. 4, Article ID 041913, 3 pages, 2006.

[31] K. M. Zhang, D. Z. Yang, J. X. Zou, T. Grosdidier, and C. Dong, "Improved in vitro corrosion resistance of a NiTi alloy by high current pulsed electron beam treatment," Surface and Coatings Technology, vol. 201, no. 6, pp. 3096-3102, 2006.

[32] K. Zhang, J. Zou, T. Grosdidier, C. Dong, and D. Yang, "Improved pitting corrosion resistance of AISI 316L stainless steel treated by high current pulsed electron beam," Surface and Coatings Technology, vol. 201, no. 3-4, pp. 1393-1400, 2006.

[33] J. X. Zou, T. Grosdidier, B. Bolle, K. M. Zhang, and C. Dong, "Texture and microstructure at the surface of an AISI D2 steel treated by high current pulsed electron beam," Metallurgical and Materials Transactions A, vol. 38, no. 9, pp. 2061-2071, 2007.

[34] J. Zou, T. Grosdidier, K. Zhang, and C. Dong, "Mechanisms of nanostructure and metastable phase formations in the surface melted layers of a HCPEB-treated D2 steel," Acta Materialia, vol. 54, no. 20, pp. 5409-5419, 2006.

[35] C. Dong, A. Wu, S. Hao et al., "Surface treatment by high current pulsed electron beam," Surface and Coatings Technology, vol. 163-164, pp. 620-624, 2003.

[36] S. Z. Hao, B. Gao, A. M. Wu et al., "Surface modification of steels and magnesium alloy by high current pulsed electron beam," Nuclear Instruments and Methods in Physics Research B, vol. 240, no. 3, pp. 646-651, 2005.

[37] R. C. Newman, "Beyond the kitchen sink," Nature, vol. 415, no. 6873, pp. 743-744, 2002.
[38] S. Hao, P. Wu, J. Zou, T. Grosdidier, and C. Dong, "Microstructure evolution occurring in the modified surface of $316 \mathrm{~L}$ stainless steel under high current pulsed electron beam treatment," Applied Surface Science, vol. 253, no. 12, pp. 5349-5354, 2007.

[39] K. M. Zhang, J. X. Zou, T. Grosdidier et al., "Mechanisms of structural evolutions associated with the high current pulsed electron beam treatment of a NiTi shape memory alloy," Journal of Vacuum Science and Technology A, vol. 25, no. 1, pp. 28-36, 2007.

[40] C. H. Hsu and F. Mansfeld, "Concernng the conversion of the constant phase element parameter Y0 into a capacitance," Corrosion, vol. 57, no. 9, pp. 747-748, 2001.

[41] G. E. Cavigliasso, M. J. Esplandiu, and V. A. Macagno, "Influence of the forming electrolyte on the electrical properties of tantalum and niobium oxide films: an EIS comparative study," Journal of Applied Electrochemistry, vol. 28, no. 11, pp. 1213-1219, 1998.

[42] K. M. Zhang, J. X. Zou, T. Grosdidier, C. Dong, and S. Weber, "Ti surface alloying of an AISI 316L stainless steel by low energy high current pulsed electron beam treatment," Journal of Vacuum Science and Technology A, vol. 26, no. 6, pp. 14071414, 2008.

[43] J. X. Zou, T. Grosdidier, B. Bolle, K. M. Zhang, and C. Dong, "Texture and microstructure at the surface of an AISI D2 steel treated by high current pulsed electron beam," Metallurgical and Materials Transactions A, vol. 38, no. 9, pp. 2061-2071, 2007.

[44] Q. F. Guan, H. Zou, G. T. Zou et al., "Surface nanostructure and amorphous state of a low carbon steel induced by high-current pulsed electron beam," Surface and Coatings Technology, vol. 196, no. 1-3, pp. 145-149, 2005.

[45] G. Z. Tang, F. J. Xu, G. H. Fan, X. X. Ma, and L. Q. Wang, "Mechanisms of microstructure formations in M50 steel melted layer by high current pulsed electron beam," Nuclear Instruments and Methods in Physics Research B, vol. 288, pp. 1-5, 2012.

[46] K. M. Zhang, J. X. Zou, T. Grosdidier, and C. Dong, "Crater formation induced metastable structure in an AISI D2 steel treated with a pulsed electron beam," Vacuum, vol. 86, pp. 12731277, 2012.

[47] J. X. Zou, K. M. Zhang, S. Z. Hao, C. Dong, and T. Grosdidier, "Mechanisms of hardening, wear and corrosion improvement of $316 \mathrm{~L}$ stainless steel by low energy high current pulsed electron beam surface treatment," Thin Solid Films, vol. 519, no. 4, pp. 1404-1415, 2010.

[48] Y. Hao, B. Gao, G. F. Tu, H. Cao, S. Z. Hao, and C. Dong, "Surface modification of Al-12. 6Si alloy by high current pulsed electron beam," Applied Surface Science, vol. 258, no. 6, pp. 2052-2056, 2012.

[49] Y. Hao, B. Gao, G. F. Tu, S. W. Li, S. Z. Hao, and C. Dong, "Surface modification of Al-20Si alloy by high current pulsed electron beam," Applied Surface Science, vol. 257, no. 9, pp. 39133919, 2011.

[50] K. M. Zhang and J. X. Zou, "Formation of ultrafine twinned austenite on a cold rolled $316 \mathrm{~L}$ stainless steel induced by pulsed electron beam treatment under heating mode," Thin Solid Films, vol. 526, pp. 28-33, 2012. 

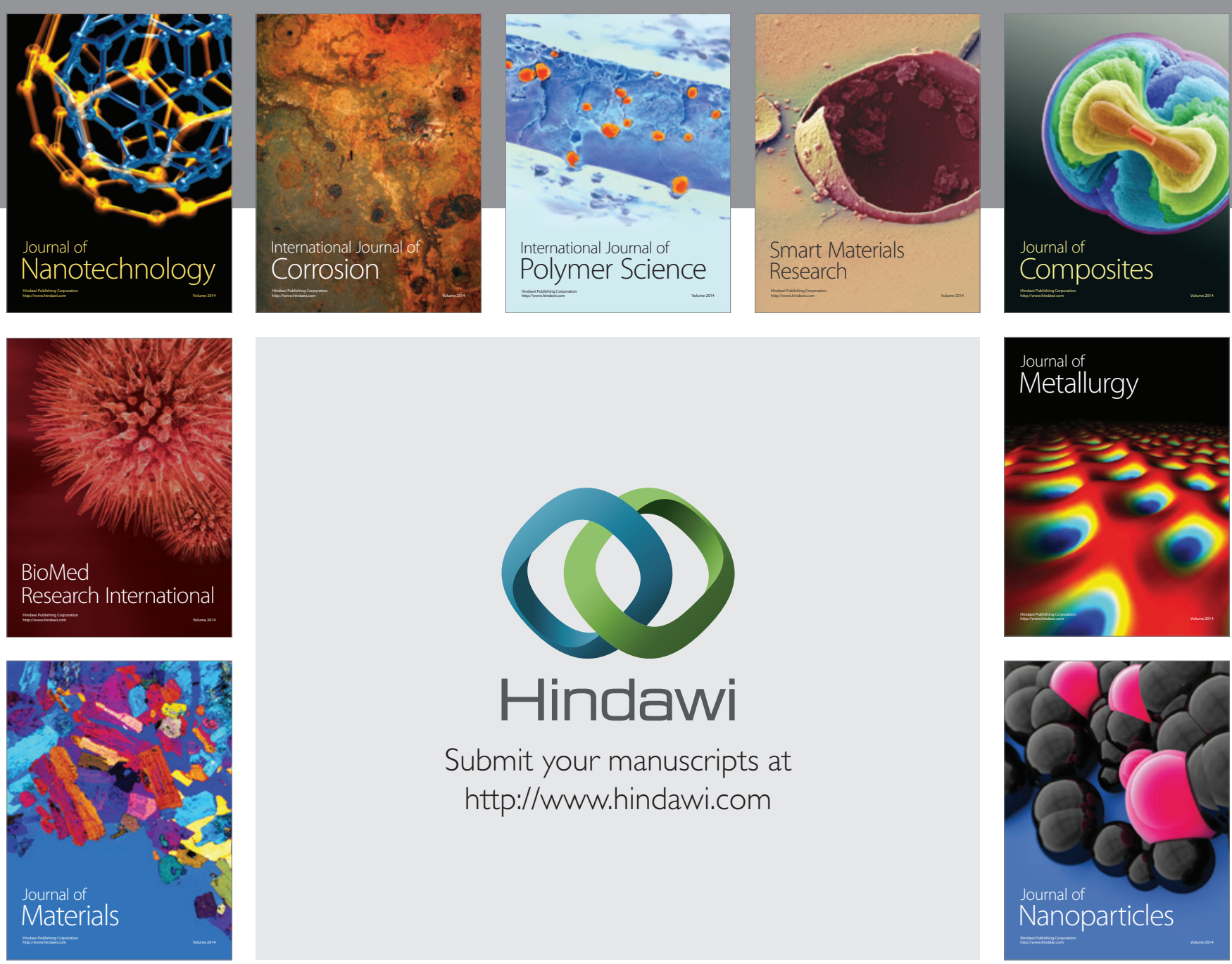

Submit your manuscripts at http://www.hindawi.com
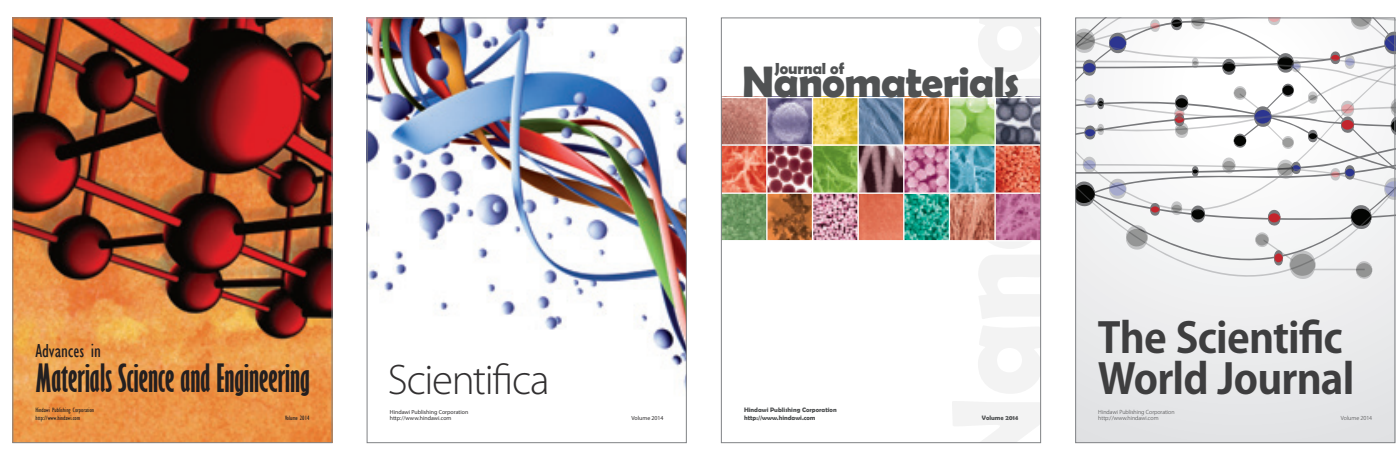

\section{The Scientific World Journal}
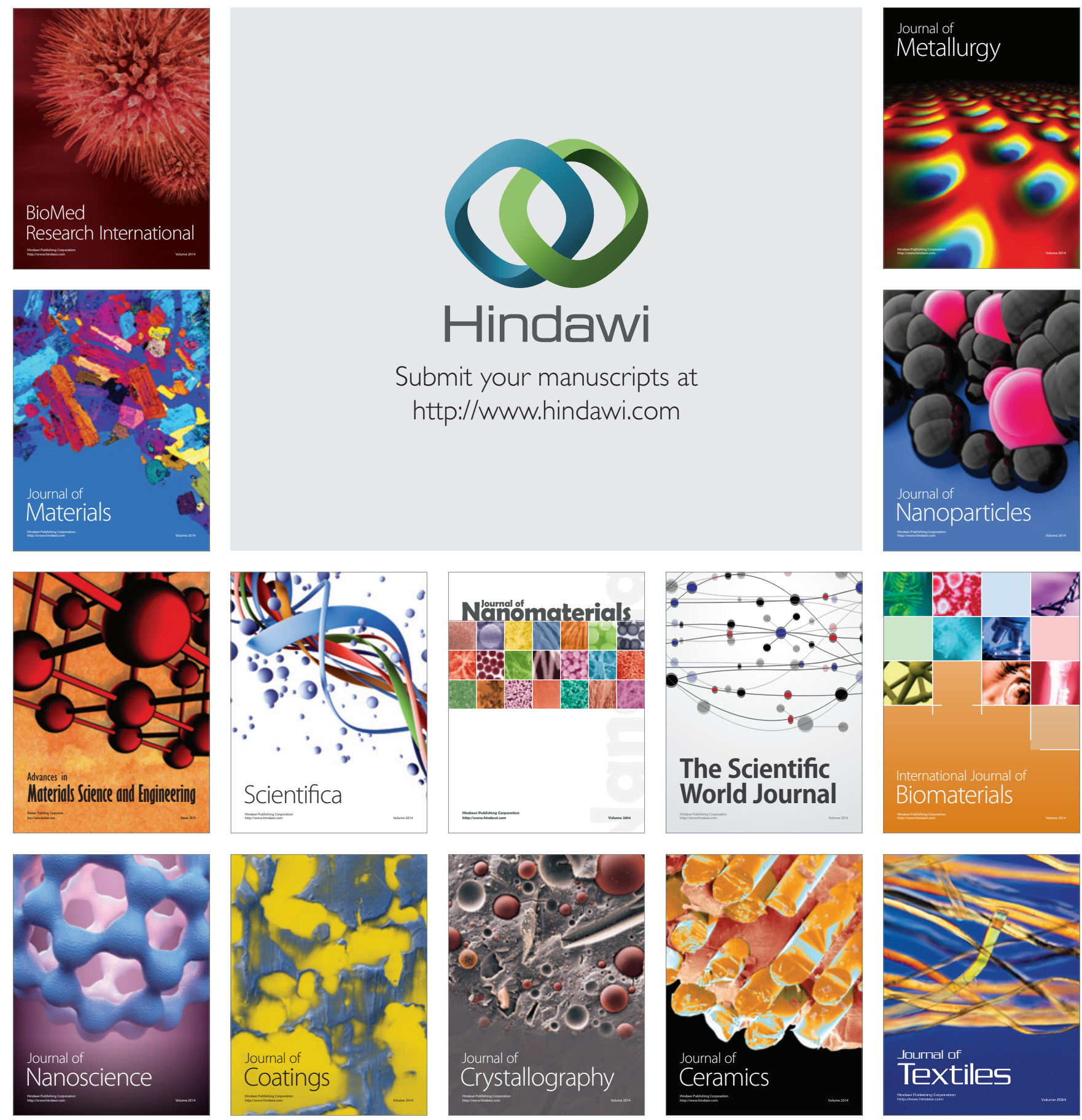